\title{
Influence of erosive fluidization on the morphology of fluid flow and escape structures
}

${ }^{1}$ Helmholtz Center for Ocean Research GEOMAR, Kiel, Germany

${ }^{2}$ Department of Geosciences, University of Malta, Msida, Malta

Key Points:

- We model the formation of fluid escape structures (FES) like pipes, chimneys and pockmarks.

- Model predicts pulsed gas flow and morphological features like conical pipe/chimney, annular gas channel, and W-, U-, ring-shaped pockmarks.

- Morphology of FES depends on sediment-fluid interactions (e.g. erodibility, anisotropy), not on intrinsic properties (e.g. permeability).

Corresponding author: Shubhangi Gupta, sgupta@geomar.de 


\section{Abstract}

Mechanisms of fluid flow localization and pockmark formation remain an open question. Many conceptual models have been proposed, but very few predictive models exist. We propose a model based on erosive fluidization where seepage induced erosion, fluidization, and transport of granular material leads the formation of fluid escape structures (FES) like pipes, chimneys and pockmarks. The model predicts: 1) formation of conical focused flow conduits with brecciated core and annular gas channels encased within a halo of low permeability sediment, 2) pockmarks of diverse shapes and sizes, including W-, U-, and ring-shapes, and 3) pulsed gas release. Results show that the morphology of FES depends on properties related to sediment-fluid interactions (like erodibility and flow anisotropy), not on intrinsic sediment properties (like permeability). Although the study is theoretical, we show that our predicted FES have many real world analogs, highlighting the broad scope of the predictive capability of our model.

\section{Plain Language Summary}

Pockmarks are seafloor manifestations of subsurface fluid flow, typically found on top of focused flow conduits (pipes and chimneys), suggesting that the formation of pipes, chimneys, and pockmarks are inherently interlinked. Pockmarks are found worldwide and exhibit wide variability in shapes, sizes, and structure, making their characterization hard and quantitative analysis harder. Many conceptual models have been proposed to explain the observed pockmarks, seismic pipes and chimneys, but surprisingly few predictive models exist. Here, we propose a mathematical model based on the mechanism of erosive fluidization, where seepage of fluids erodes the sediment, and the eroded sediment particles are fluidized, transported, and redeposited. This redistribution of the sediment mass leads to localization of fluid flow, evolution of pipes and chimneys, and formation of pockmarks. Through numerical studies of idealized scenarios, we show that this model can not only simulate the formation of focused flow conduits and pockmarks of different shapes and sizes, but also makes important predictions regarding the role of intrinsic sediment characteristics (like permeability) vis-a-vis characteristics of sedimentfluid interactions (like sediment erodibility and flow anisotropy). Although this study is theoretical, we show that the results are widely applicable with many real world analogs based in diverse geological settings. 


\section{Introduction}

Pockmarks are bathymetric depressions on the seafloor formed due to venting of subsurface fluids, which is accompanied by erosion and removal of sediment (Judd \& Hovland, 2007). They are found worldwide on the floors of active or relict oceans and lakes (Sultan et al., 2014; Reusch et al., 2015; Böttner et al., 2019; Callow et al., 2021), and exhibit wide variability in their shapes and sizes (Gafeira et al., 2018). Pockmarks typically form on top of focused fluid conduits, which appear in seismic data as pipes or chimneys (K. J. Andresen, 2012; Karstens \& Berndt, 2015; Cartwright \& Santamarina, 2015), generally attributed to localized release of overpressure in the subsurface through hydraulic connection of deeper sediment layers with the seafloor (Cathles et al., 2010). These conduits are efficient pathways for fluid migration from deeper sediments to the seafloor and atmosphere, and are therefore, critical for constraining global carbon emissions (Berndt, 2005). Due to active fluid and hydrocarbon emissions, they are important ecological hotspots (Berndt, 2005), indicators of hydrocarbon reservoirs (Judd \& Hovland, 2007; Strozyk et al., 2018), and potential geohazard for offshore operations (Vanneste et al., 2014; Roelofse et al., 2020).

Most field observations of pockmarks and seismic pipes/chimneys have been qualitatively explained using conceptual models based on mechanisms like capillary invasion, hydraulic fracturing, erosive fluidization, and local volume loss (e.g., due to carbonate dissolution or hydrate melting, etc.) (e.g., (K. Andresen et al., 2021; Cartwright \& Santamarina, 2015) and references therein). However, surprisingly few predictive models can actually simulate the initiation and propagation of focused flow, and even fewer can resolve the evolution of pockmarks. Currently, two prominent models deal with the formation of pipes/chimneys: 1) based on hydraulic fracturing hypothesis where overpressured gas in the source rock induces fractures in the overburden, and a network of hydraulic fractures propagates towards the surface as high-permeability conduits (Wangen, 2020), and 2) based on the concept of solitary porosity waves where self-propagating highporosity, high-permeability channels emerge spontaneously due to complex nonlinear coupling between fluid buoyancy, asymmetric compaction-decompaction of pores, and viscoplastic deformations of sediment matrix (e.g., (Räss et al., 2019; Yarushina et al., 2021)). Although not explicitly resolved, pockmarks appear in these models as a consequence of localized mechanical deformations within focused flow conduits. While these models are highly sophisticated and capture interesting dynamics related to flow localization, 
they completely ignore aspects of erosive fluidization and sediment transport. Fluidization is ubiquitous in geological subsurface (McCallum, 1985). Pockmarks and pipes/chimneys are primarily considered to be erosive structures (Judd \& Hovland, 2007), and there is evidence of mud slurry transport (Roberts et al., 2010) and complete or partial loss of stratigraphy within focused flow conduits due to fluidization and brecciation (Huuse et al., 2005).

To the best of our knowledge, no predictive models have considered focused fluid flow and pockmark formation through erosive fluidization. To address this gap, we propose a mathematical framework that can resolve flow localization through internal erosion and fluidization, and simulate the evolution of seafloor and subsurface morphology through sediment redistribution. Using numerical simulations of an idealized pockmark formation scenario, we analyze the influence of sediment-fluid interactions on the morphology of fluid flow and escape structures.

\section{Methodology}

\subsection{Mathematical Model}

To model the physics of erosive fluidization, we conceptualize the subsurface sediment as an additive decomposition of two distinct physical states (or phases): 1) Intact sediment, where the porous structure is preserved, and 2) fluidized sediment, where the porous fabric is destroyed and granular material is suspended in water in a muddy-slurry. Phase transitions between intact and fluidized sediment states are controlled by erosion due to fluid seepage, and deposition due to limited carrying capacity of pore-fluids. Fluid flow drives phase transitions and leads to conservative redistribution of the granular material, affecting surface and subsurface morphology.

This conceptual model is formalized through a generalized mathematical framework where coupled fluid flow, sediment-fluid interactions, and conservative sediment transport are described within the macroscopic theory of porous media, and the changing seafloor morphology is resolved as a manifestation of the redistribution of aggregate sediment mass.

Domain of interest $\Omega \subset \mathbb{R}^{d}$ with $d=\{1,2,3\}$, is partitioned into two non-overlapping sub-domains: Free-flow domain $\Omega_{w} \subset \Omega$ and porous domain $\Omega_{p} \subset \Omega$, s.t., $\Omega_{w} \cup \Omega_{p}=$ $\Omega$ and $\Omega_{w} \cap \Omega_{p}=\emptyset$. Inner boundary between these sub-domains, $\Gamma_{w p} \subset \mathbb{R}^{d-1}$, is instationary, evolving over time due to continuous sediment redistribution. The domain 
and the associated homogenized representative elementary volume (REV) are described in Fig.1).

Three distinct phases are considered: 1) water, denoted by subscript ' $w$ ', 2) an 'invading' phase (e.g. gas, light hydrocarbons, etc.) by 'n', and 3) continuum sediment phase by 's'. Furthermore, within the scope of this study, the invading phase is assumed to be gaseous (much lighter than water). Therefore, eroded sediment particles, denoted by 'f', are fluidized only within w-phase. There is continuous exchange of mass between intact and fluidized sediment through erosion (by seepage of invading phase) and deposition (of particles suspended in water phase). The main governing equations, which include mass conservation statements for w-, n-, and s- phases and f-component, are as follows:

$$
\begin{aligned}
\partial_{t} \phi \rho_{w} S_{w}+\nabla \cdot \rho_{w} \mathbf{v}_{w} & =0 \\
\partial_{t} \phi \rho_{n}\left(1-S_{w}\right)+\nabla \cdot \rho_{n} \mathbf{v}_{n} & =0 \\
\partial_{t}(1-\phi) \rho_{s} & =-\epsilon_{n}+\delta_{w} \\
\partial_{t} \phi \rho_{w} S_{w} \Theta_{f}+\nabla \cdot \rho_{w} \mathbf{v}_{w} \Theta_{f} & =\epsilon_{n}-\delta_{w}
\end{aligned}
$$

with, local porosity $\phi$, wetting phase saturation $S_{w}, 1$ mass fraction of the sediment suspended in water $\Theta_{f}$, phase densities $\rho_{(\cdot)}$ s.t., $\frac{\rho_{n}}{\rho_{w}} \ll 1$, phase velocities $\mathbf{v}_{(\cdot)}$, and erosion and deposition rates $\epsilon_{n}$ and $\delta_{w}$.

Sub-surface fluid seepage is characterized by low Reynolds numbers and can be modelled using Darcy's law (Helmig, 1997). In the surface domain, families of Darcy-BrinkmannStokes models are considered more accurate when surface water run-off is dominant compared to sub-surface fluid seepage. However, in this study we ignore bottom water currents, and therefore, assume that Darcy model is sufficient to resolve phase velocities in both sub-domains, such that,

$$
\begin{aligned}
& \text { for each } \alpha=\{w, n\}, \quad \mathbf{v}_{\alpha}=-\mathbf{K} \frac{k_{r \alpha}}{\mu_{\alpha}}\left(\nabla P_{\alpha}+\rho_{\alpha} \mathbf{g}\right) \\
& \text { where, } \quad K_{i}=K_{0, i} \exp \left[a_{0, i}\left(\frac{\phi-\phi_{0}}{1-\phi_{0}}\right)\right] \quad \text { for each } i \in d \\
& \text { and, } \quad k_{r w}=S_{w}^{(2 / \lambda+3)} \\
& k_{r n}=\left(1-S_{w}\right)^{2}\left(1-S_{w}^{(2 / \lambda+1)}\right)
\end{aligned}
$$

where, $\mathbf{K}$ is the intrinsic permeability (defined as a $d$-dimensional diagonal matrix), $K_{0, i}$ and $\phi_{0}$ are 'reference' permeability and porosity of the intact sediment, and $a_{0, i}$ is a model parameter which controls the range of permeability variation w.r.t. porosity(Hommel et 
al., 2018). Note, when $\phi=\phi_{0}, K_{i}=K_{i, 0}$, and when $\phi=1, K_{i}:=K_{i, \max }=K_{0, i} \exp \left(a_{0, i}\right)$. Finally, $\mu_{(\cdot)}$ are phase viscosities and $k_{r(\cdot)}$ the relative permeabilities (Helmig, 1997) with material parameter $\lambda$ related to the particle size distribution.

Phase pressures $P_{(\cdot)}$ are related through a pressure jump, called capillary pressure, across the fluid-fluid phase boundaries, s.t.,

$$
P_{n}-P_{w}:=p_{c}\left(\phi, S_{w}\right)
$$

where, $p_{c}$ can be modelled using empirical or analytical parameterizations (Helmig, 1997). Our general model implicitly resolves capillary pressure, but within this study, capillary effects are ignored (i.e., $p_{c}:=0$ ) to highlight the role of erosive fluidization in flow localization, as opposed to the capillary hypothesis (Cathles et al., 2010).

Finally, erosion and deposition rates are modelled as (see (Rahmati et al., 2013) and references therein),

$$
\begin{aligned}
& \epsilon_{n}=e_{0}(1-\phi)^{m}\left|\frac{\mathbf{v}_{n}}{v_{c}}\right|^{n} \\
& \delta_{w}=d s_{0}\left(\frac{\Theta_{f}}{\phi S_{w}}\right)^{\gamma}
\end{aligned}
$$

with, internal erosion and deposition rate constants $e_{0}$ and $d s_{0}$, characteristic seepage $v_{c}$, and empirical parameters $m, n$ and $\gamma$.

\subsection{Numerical Scheme}

Governing equations (1)-(4) were discretized using fully-upwinded cell-centered finite volume scheme, with $P_{w}, S_{w}, \phi$, and $\Theta_{f}$ as primary variables. To evaluate erosion rates, fluid velocity fields were reconstructed using an $L 2$-projection of the phase pressures from their native $P 0$-space to a higher $Q 1-$ space. The discrete model was partitioned into three sub-modules: 1) two-phase flow module composed of the governing equations (1),(2) with primary variables $\left.\mathcal{P}_{1}=\left[P_{w}, S_{w}\right]^{T}, 2\right) L 2$-projection module with projected phase pressures as 'intermediate' primary variables $\mathcal{P}_{2}=\left[\bar{P}_{w}, \bar{P}_{n}\right]^{T}$, and 3) sediment transport module composed of governing equations (3),(4) with primary variables $\mathcal{P}_{3}=\left[\phi, \Theta_{f}\right]^{T}$. The solution of the coupled problem was obtained by solving the sub-modules iteratively at each time-step using a blocked Gauss-Seidel method (Gupta et al., 2015). The numerical scheme was implemented in C++ based DUNE-PDELab (Sander, 2020), and used in-built matrix assembler and solvers (Newton and parallel Algebraic Multi-Grid). 


\subsection{Computational Setting}

An idealized geological test setting (see Fig. 1) is considered where a light hydrocarbon (e.g. methane gas) is trapped under high pressure in a source rock layer sealed by a capillary barrier. The overlying sediment is assumed to be stratigraphically homogeneous, fully water saturated, and continuously connected to the seafloor. At $t=0$, a fracture spontaneously punctures the capillary barrier and allows the escape of overpressured gas. We identify a $2 \mathrm{D}$ computational domain $\Omega$ as a region around the fracture, located just above the capillary barrier. Computational domain encompasses the overburden $\Omega_{p}$ as well as the water column $\Omega_{w}$, and implicitly resolves the seafloor $\Gamma_{w p}$. Numerical parameters and material properties are summarized in Fig. 1. Reference permeabilities are chosen such that a broad range of continental shelf sediments are represented (Dutkiewicz et al., 2015).

Here, we only focus on flow localization within $\Omega_{p}$ and evolution of $\Gamma_{w p}$ due to sediment redistribution. We do not resolve the source of free gas in the source rock and the cause of the fracture. Moreover, to isolate the effects of internal erosion, we also ignore bottom water currents in $\Omega_{w}$ in the vicinity of $\Gamma_{w p}$.

\section{Results and discussion}

Simulations demonstrate the mechanism of erosive fluidization, where seepage of overpressured gas causes erosion of the sediment and subsequent fluidization, transport, and deposition of eroded soil particles. Distinct focused flow conduits open up in the subsurface and pockmarks appear at the seafloor. Figs. 2 and 3 show selected results from scenarios with $K_{0,1}=10^{-13} \mathrm{~m}^{2}$, with an extended selection included in the Supplementary Material. Effects of erosive fluidization are analyzed in terms of $r_{0}:=\frac{e_{0}}{d s_{0}}$ (erosion vs deposition rate constants) and $K_{F}:=\frac{K_{0,0}}{K_{0,1}}$ (lateral vs vertical permeability), where $r_{0}$ compares relative erodibility of granular material and $K_{F}$ measures sediment anisotropy and stratigraphic layering. Results show that even for the same geological setting, gas source, and sediment hydraulic characteristics (i.e., permeability, porosity, etc.), the morphological manifestations of fluid-flow may not be unique. Rather, variability in sediment-fluid interactions can result in large differences in flow localization, gas fluxes, and pockmarks. Based on the numerical results, our key findings are: 
1. Erosive fluidization leads to characteristic morphological features like conical focused-flow pathway with annular gas flow that may be interpreted as gas pipe/chimney, encased in a halo of low permeability sediment that acts as a seal against lateral gas transport. Figs. 2-A and 3-A show the focused-flow pathway and sediment halo, while Figs. 2-B and 3-B highlight the annular gas channels. The sediment within the focused flow pathways undergoes intense seepage driven mixing, resulting in partial or total loss of stratigraphic structure and brecciation. These features bear striking similarities with the sand-box experiments analyzing formation of piercement structures through controlled fluidization (McCallum, 1985; Nermoen et al., 2010).

2. Erosion and deposition are competing processes with complex feedbacks. Higher relative erosion vs deposition $\left(r_{0}\right)$ leads to more prominent cylindrical focused-flow pathway with a 'tight' halo; whereas, higher sediment anisotrpy $\left(K_{F}\right)$ leads to wider focused-flow pathway with wide and more diffuse sediment halo. In literature, the terms 'chimney' and 'pipe' are often used interchangeably for focused flow pathways, although some authors (e.g., (K. Andresen et al., 2021; Karstens \& Berndt, 2015)) consider a stricter nomenclature where pipe refers to cylindrical flow conduits with sharp boundary between focused flow zone and host sediment, and chimney refers to conduits with chaotic transition. Based on this nomenclature, our results suggest that high $r_{0}$ leads to pipes and high $K_{F}$ leads to chimneys, although transition between the two structures is continuous.

On the seafloor, higher $r_{0}$ leads to narrower pockmarks with sharp depressions, whereas variations of $K_{F}$ show more complex trends: If $r_{0}$ is high and $K_{F}$ is low, sediment collects on the rim of the pockmark, forming a raised ring-shaped encasing. As $K_{F}$ increases, more and more lateral transport occurs leading to 'flattening' of the ring, formation of secondary rings, and eventually, large lateral extension of the pockmarks. On the other hand, as $r_{0}$ decreases, smaller sediment mass reaches the surface and ringed pockmarks do not form. For small enough $r_{0}$, deposition exceeds erosion, which leads to reversal of the effect of increasing sediment anisotropy on lateral extension, leading to narrower and shallower pockmarks.

3. Differences in sediment-fluid interactions lead to diversity in pockmark shapes and sizes. Within the constraints of this test setting, two interesting pockmark geometries emerge, $\mathrm{W}$-shaped and ring-shaped. 
- W-shaped pockmarks are widespread in nature (e.g., (Watson et al., 2020; Gafeira et al., 2018)), and are associated with active fluid escape (Lazar et al., 2019; Schattner et al., 2012). In plan-view, such pockmarks are reported as either radially symmetric (e.g., Fig.4-A4) or as pockmark-pairs (e.g., Fig.4-A2,3,5). Our results suggest that the depression of the annular gas channel follows radial symmetry. However, as the depressions become sharper, pockmarks can deviate from their radial symmetry and localize to form pockmark-pairs. An example in literature where our results apply is a $\sim 60 \mathrm{~m}$ across and $\sim 10 \mathrm{~m}$ deep, radially symmetric, W-shaped pockmark reported offshore northern Israel (Schattner et al., 2012) (see Fig.4-A4)). This geological setting has many similarities with our idealized scenario like, the pockmark is linked to active venting of methane gas, is located on seabed in shallow water depth $(<100 \mathrm{~m})$, and sits directly above a chimney originating just above the LGM (last glacial maxima) uncomformity at depths between 100 and $200 \mathrm{~m}$. Another example is a pockmark-pair reported in the Scanner region (Callow et al., 2021) (Fig.4-A3), also linked with active venting of methane-rich gas. More strikingly, gas escape from this pockmark exhibits an episodic character.

- While the inverted-dome in the center of the pockmarks is an intrinsic feature of active-fluid escape, our model suggests that for high $K_{F}$ and low $r_{0}$, this dome becomes flatter such that the $\mathrm{W}$-shape transitions to a U-shape with a wide and shallow base. Fig. 4-C1 shows an example of a shallow U-shaped pockmark reported in Sea of Galilee (Lazar et al., 2019). Such shallow U-shaped pockmarks are linked to active fluid escape, and are therefore, different from the inactive $\mathrm{V}$-shaped pockmarks that transition to U-shape through surface erosion from bottom water currents.

- Our results show that erosive fluidization can lead to ring-shaped pockmarks, and predict that these can emerge in sediments with a combination of high erodibility and low anisotropy. Occurrence of such pockmarks is relatively rare, with Hudson Bay being a rather prominent example (Fig.4-B1), where these pockmarks likely formed in post glacial times due to movement of icebergs that may have breached capillary seals, allowing escape of unknown hydrocarbon fluids from source rocks possibly located at depths of $\sim 80-200 \mathrm{~m}$ (Roger et al., 2011). In Hudson Bay, the Holocene sediments (surficial deposits of 6-20m and bank 
and barrier deposits of $200 \mathrm{~m}$ thickness) are made of unconsolidated layers of fine sandy to silty clays that are highly susceptible to erosion. Moreover, the surficial deposits are acoustically transparent, suggesting little to no stratigraphic layering. Both these sediment characteristics are qualitatively congruent with our prediction.

4. Gas release occurs in pulses (Figs. 2-D, 3-D). A combination of low $r_{0}$ and high $K_{F}$ lead to higher amplitude (black curves), while high $r_{0}$ and high $K_{F}$ lead to higher frequency of gas pulses. In nature, periodicity of high frequency gas pulses is likely masked by the bottom water currents. However, our results suggest that the pulsed release of gas is an intrinsic feature of the physics of flow localization through erosive fluidization. Interestingly, this pulsed gas release was also reported in the experiments by Nermoen et al., (2010), and the simulated localization of gas in the subsurface closely resembles the air ascent imaged in these experiments (Fig. 4-D1).

5. Finally, our results show that intrinsic permeability $K_{0,1}$ does not impact the shape and size of fluid escape structures (Fig.5-A). It only affects the time-scale of flow localization. Furthermore, the morphology of pockmarks and pipes/chimneys is controlled by the ratio of $e_{0}$ and $d s_{0}$ (i.e., $\left.r_{0}\right)$ and not by their individual magnitudes. This strongly suggests that the morphology of the fluid escape structures depends on the properties controlling sediment-fluid interactions, like erodability and flow anisotropy, rather than the intrinsic sediment properties like permeability. Interestingly, differences do appear in the gas flow behaviour (Fig.5-B), with lower $K_{0,1}$ leading to higher frequency and lower $e_{0}$ (or conversely higher $d s_{0}$ ) leading to higher amplitude gas pulses.

\section{Conclusions}

We presented a mathematical model for simulating flow localization and pockmarks formation through erosive fluidization and sediment redistribution. Numerical simulations of an idealized scenario of gas escape from over-pressured source rock showed 1) formation of conical focused flow conduits with brecciated core and annular gas channels encased within a halo of low permeability sediment; 2) pockmarks of diverse shapes and sizes on the seafloor, including W-, U-, and ring-shapes; and 3) a pulsed release of gas. Results highlight the dominant role of sediment-fluid interactions. In particular, they 
suggest that evolution of surface and subsurface morphologies depends on flow anisotropy but not on intrinsic permeability. Although theoretical, our results have striking realworld analogs in nature as well as controlled experiments.

\section{Open Research}

Version 2.8 of the C++ based 'DUNE-PDElab' toolbox was used for the implementation of the numerical scheme described in Sec. 2.2. This version is preserved at https:// gitlab.dune-project.org/pdelab/dune-pdelab and developed openly at https:// www .dune-project.org/. The archiving of the source code for the model and test scenarios presented in this manuscript is underway in the following public repository: https:// git.geomar.de/shubhangi-gupta/erosivefluidizationmodel.git.

\section{Acknowledgments}

We acknowledge funding from the European Research Council (grant No 677898 (MARCAN)) under European Union's Horizon 2020 research program.

\section{References}

Andresen, K., Dahlin, A., Kjeldsen, K., Røy, H., Bennike, O., Nørgaard-Pedersen, N., \& Seidenkrantz, M.-S. (2021). The longevity of pockmarks - a case study from a shallow water body in northern denmark. Marine Geology, 434, 106440. doi: 10.1016/j.margeo.2021.106440

Andresen, K. J. (2012). $\quad$ Fluid flow features in hydrocarbon plumbing systems: What do they tell us about the basin evolution? Marine Geology, 332-334, 89108. (Hydrocarbon leakage through focused fluid flow systems in continental margins) doi: 10.1016/j.margeo.2012.07.006

Berndt, C. (2005). Focused fluid flow in passive continental margins. Philosophical Transactions of the Royal Society A: Mathematical, Physical and Engineering Sciences, 363(1837), 2855-2871. doi: 10.1098/rsta.2005.1666

Böttner, C., Berndt, C., Reinardy, B. T., Geersen, J., Karstens, J., Bull, J. M., ... Haeckel, M. (2019). Pockmarks in the witch ground basin, central north sea. Geochemistry, Geophysics, Geosystems, 20(4), 1698-1719. doi: 10.1029/2018GC008068

Callow, B., Bull, J. M., Provenzano, G., Böttner, C., Birinci, H., Robinson, A. H., 
... Berndt, C. (2021). Seismic chimney characterisation in the north sea implications for pockmark formation and shallow gas migration. Marine and Petroleum Geology, 133, 105301. doi: 10.1016/j.marpetgeo.2021.105301

Cartwright, J., \& Santamarina, C. (2015). Seismic characteristics of fluid escape pipes in sedimentary basins: Implications for pipe genesis. Marine and Petroleum Geology, 65, 126-140. doi: 10.1016/j.marpetgeo.2015.03.023

Cathles, L., Su, Z., \& Chen, D. (2010). The physics of gas chimney and pockmark formation, with implications for assessment of seafloor hazards and gas sequestration. $\quad$ Marine and Petroleum Geology, 27(1), 82-91. doi: 10.1016/j.marpetgeo.2009.09.010

Dutkiewicz, A., Müller, R. D., O’Callaghan, S., \& Jónasson, H. (2015, 09). Census of seafloor sediments in the world's ocean. Geology, 43(9), 795-798. doi: 10 $.1130 / \mathrm{G} 36883.1$

Gafeira, J., Dolan, M. F. J., \& Monteys, X. (2018). Geomorphometric characterization of pockmarks by using a gis-based semi-automated toolbox. Geosciences, 8(5). doi: 10.3390/geosciences8050154

Gupta, S., Helmig, R., \& Wohlmuth, B. (2015). Non-isothermal, multi-phase, multi-component flows through deformable methane hydrate reservoirs. Computational Geosciences, 19, 1063-1088. doi: 10.1007/s10596-015-9520-9

Helmig, R. (1997). Multiphase flow and transport processes in the subsurface. A contribution to the modeling of hydrosystems. Springer Berlin Heidelberg.

Hommel, J., Coltman, E., \& Class, H. ～(2018). Porosity-permeability relations for evolving pore space: A review with a focus on (bio-)geochemically altered porous media. $\quad$ Transp Porous Med, 124, 589-629. doi: 10.1007/ s11242-018-1086-2

Huuse, M., Shoulders, S. J., Netoff, D. I., \& Cartwright, J. (2005). Giant sandstone pipes record basin-scale liquefaction of buried dune sands in the middle jurassic of se utah. Terra Nova, 17(1), 80-85.

Judd, A., \& Hovland, M. (2007). Seabed fluid flow: The impact on geology, biology and the marine environment. Cambridge University Press.

Karstens, J., \& Berndt, C. (2015). Seismic chimneys in the southern viking graben - implications for palaeo fluid migration and overpressure evolution. Earth and Planetary Science Letters, 412, 88-100. doi: 10.1016/j.epsl.2014.12.017 
Lazar, M., Gasperini, L., Polonia, A., Lupi, M., \& Mazzini, A. (2019). Constraints on gas release from shallow lake sediments - a case study from the sea of galilee. Geo-Marine Letters, 39, 377-390. doi: 10.1007/s00367-019-00588-w

McCallum, M. (1985). Experimental evidence for fluidization processes in breccia pipe formation. Economic Geology, 80(6), 1523-1543.

Nermoen, A., Galland, O., Jettestuen, E., Fristad, K., Podladchikov, Y., Svensen, H., \& Malthe-Sørenssen, A. (2010). Experimental and analytic modeling of piercement structures. Journal of Geophysical Research: Solid Earth, $115(\mathrm{~B} 10)$.

Rahmati, H., Jafarpour, M., Azadbakht, S., Nouri, A., Vaziri, H., Chan, D., \& Xiao, Y. (2013). Review of sand production prediction models. Journal of Petroleum Engineering, 19, ID 864981, 16 pages. doi: 10.1155/2013/864981

Reusch, A., Loher, M., Bouffard, D., Moernaut, J., Hellmich, F., Anselmetti, F. S., ... Strasser, M. (2015). Giant lacustrine pockmarks with subaqueous groundwater discharge and subsurface sediment mobilization. Geophysical Research Letters, 42(9), 3465-3473. doi: 10.1002/2015GL064179

Roberts, K. S., Davies, R. J., \& Stewart, S. A. (2010). Structure of exhumed mud volcano feeder complexes, azerbaijan. Basin Research, 22(4), 439-451. doi: https://doi.org/10.1111/j.1365-2117.2009.00441.x

Roelofse, C., Alves, T. M., \& Gafeira, J. (2020). Structural controls on shallow fluid flow and associated pockmark fields in the east breaks area, north-

ern gulf of mexico. $\quad$ Marine and Petroleum Geology, 112, 104074. doi: 10.1016/j.marpetgeo.2019.104074

Roger, J., Duchesne, M., Lajeunesse, P., St-Onge, G., \& Pinet, N. (2011). Imaging pockmarks and ring-like features in hudson bay from multibeam bathymetry data. TGeological Survey of Canada, 19. (Open File 6760)

Räss, L., Duretz, T., \& Podladchikov, Y. (2019). Resolving hydromechanical coupling in two and three dimensions: spontaneous channelling of porous fluids owing to decompaction weakening. Geophysical Journal International, 218(3), 1591-1616. doi: 10.1093/gji/ggz239

Sander, O. (2020). Dune - the distributed and unified numerics environment. Springer International Publishing.

Schattner, U., Lazar, M., Harari, D., \& Waldmann, N. (2012). Active gas migration 
systems offshore northern israel, first evidence from seafloor and subsurface data. Continental Shelf Research, 48, 167-172. doi: https://doi.org/10.1016/ j.csr.2012.08.003

Strozyk, F., Reuning, L., Back, S., \& Kukla, P. (2018, 01). Giant pockmark formation from cretaceous hydrocarbon expulsion in the western lower saxony basin, the netherlands. Geological Society, London, Special Publications, 469, 519-536. doi: 10.1144/SP469.6

Sultan, N., Bohrmann, G., Ruffine, L., Pape, T., Riboulot, V., Colliat, J., ... Wei, J. $\quad(2014,04)$. Pockmark formation and evolution in deep water nigeria: Rapid hydrate growth versus slow hydrate dissolution: Pockmark formation and evolution. Journal of Geophysical Research: Solid Earth, 119. doi: 10.1002/2013JB010546

Vanneste, M., Sultan, N., Garziglia, S., Forsberg, C. F., \& L’Heureux, J.-S. (2014). Seafloor instabilities and sediment deformation processes: The need for integrated, multi-disciplinary investigations. Marine Geology, 352, 183-214.

Wangen, M. (2020). A 3d model for chimney formation in sedimentary basins. Computers \& Geosciences, 137, 104429. doi: 10.1016/j.cageo.2020.104429

Watson, S., Neil, H., Ribó, M., Lamarche, G., Strachan, L., Mackay, K., ... Steinmetz, T. $(2020,09)$. What we do in the shallows: Natural and anthropogenic seafloor geomorphologies in a drowned river valley, new zealand. Frontiers in Marine Science, 7, 579626. doi: 10.3389/fmars.2020.579626

Yarushina, V. M., Wang, L. H., Connolly, D., Kocsis, G., Fæstø, I., Polteau, S., \& Lakhlifi, A. $\quad(2021,10)$. Focused fluid-flow structures potentially caused by solitary porosity waves. Geology. doi: 10.1130/G49295.1 


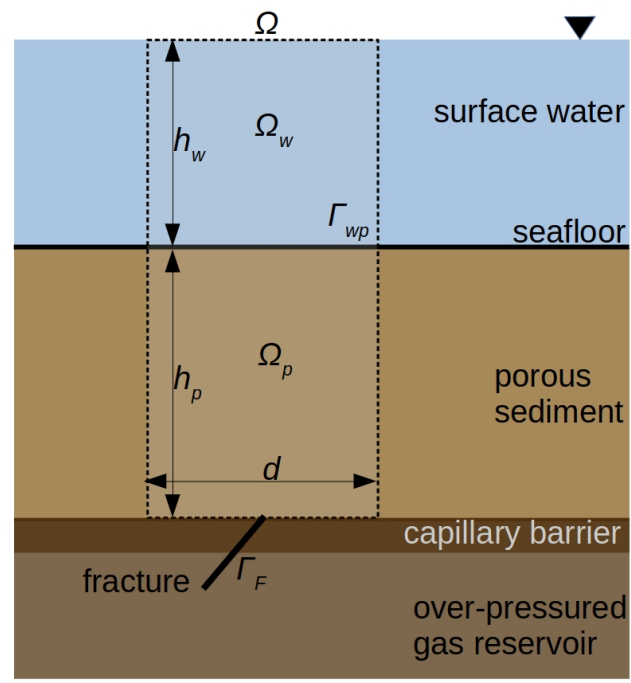

Test-setting and computational domain.

$\Omega$ denotes the 2D computational domain, composed of non-overlapping surface (free-flow) and sub-surface (porous) sub-domains $\Omega_{w}$ and $\Omega_{p}$ such that $\Omega_{w} \cup \Omega_{p}=\Omega$ and the evolving $1 \mathrm{D}$ seafloor $\Gamma_{w p}$.

Fracture $\Gamma_{F}$ (not part of $\Omega$ ) transports over-pressured gas from reservoir to the overburden porous sediment (i.e. $\Omega_{p}$ )

Values of $h_{w}, h_{p}$, and $d$ are specified in part (C) below .

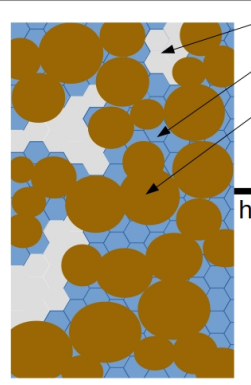

gas (n-) Water (w-)

soil grains (s-)

pore-scale

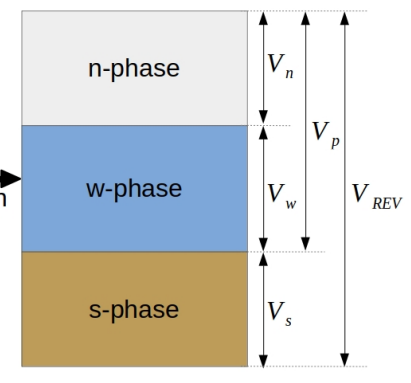

REV-scale
Representative elementary volume

\section{(REV).}

On REV scale, following homogenized variables are defined:

- Porosity $\phi(x, t)=\frac{V_{p}}{V_{R E V}}$

such that $0<\phi<1$ in $\Omega_{p}$ and $\phi=1$ in $\Omega_{w}$.

- Saturations for mobile (i.e. w- and n-) phases,

$S_{w}(\boldsymbol{x}, t)=\frac{V_{w}}{V_{p}}$ and $S_{n}(\boldsymbol{x}, t)=\frac{V_{n}}{V_{p}}$

such that $S_{w}+S_{n}=1$

\begin{tabular}{|c|c|c|c|}
\hline parameter & symbol & unit & value \\
\hline \multicolumn{4}{|c|}{ computational domain } \\
\hline height of water column & $h_{w}$ & $\mathrm{~m}$ & 100 \\
\hline height of sediment column & $h_{p}$ & $\mathrm{~m}$ & 200 \\
\hline domain width & $d$ & $\mathrm{~m}$ & 500 \\
\hline domain discretization & $\Delta x, \Delta y$ & $\mathrm{~m}, \mathrm{~m}$ & $2.5,1$ \\
\hline time steps & $\Delta t$ & s & $\begin{array}{c}\text { adaptive } \\
1 \leq \Delta t \leq 3600\end{array}$ \\
\hline excess gas pressure & $\left.\Delta P_{n}\right|_{\Gamma_{F}}$ & $\mathrm{MPa}$ & 2 \\
\hline \multicolumn{4}{|c|}{ material properties and parameters } \\
\hline reference porosity & $\phi_{0}$ & - & 0.2 \\
\hline reference permeability ${ }^{*}$ & $\begin{array}{c}K_{0,1} \\
K_{0,0}:=K_{F} K_{0,1}\end{array}$ & $\begin{array}{l}m^{2} \\
m^{2}\end{array}$ & $\begin{array}{l}10^{-13} \\
K_{F}=1,10,100\end{array}$ \\
\hline permeability model parameters & $\begin{array}{c}a_{0,1} \\
a_{0,0}:=a_{F} a_{0,1} \\
\lambda\end{array}$ & $\begin{array}{l}- \\
- \\
-\end{array}$ & $\begin{array}{c}3 \\
a_{F}=1 \\
1.2\end{array}$ \\
\hline erosion model parameters ${ }^{* *}$ & $\begin{array}{c}e_{0} \\
m \\
n \\
v_{c}\end{array}$ & $\begin{array}{l}\mathrm{kg} / \mathrm{m}^{3} \cdot \mathrm{s} \\
- \\
- \\
\mathrm{m} / \mathrm{s}\end{array}$ & $\begin{array}{c}1 \\
1 / 2 \\
1 \\
10^{-6}\end{array}$ \\
\hline $\begin{array}{l}\text { sedimentation model } \\
\text { parameters }\end{array}$ & $\begin{array}{c}d s_{0} \\
\gamma\end{array}$ & $\mathrm{kg} / \mathrm{m}^{3} \cdot \mathrm{s}$ & $\begin{array}{c}\{0.01,0.02,0.04\} \\
1\end{array}$ \\
\hline gas density & $\rho_{n}$ & $\mathrm{~kg} / \mathrm{m}^{3}$ & 10 \\
\hline water density & $\rho_{w}$ & $\mathrm{~kg} / \mathrm{m}^{3}$ & 1027 \\
\hline
\end{tabular}

\section{Material properties and test parameters.}

${ }^{*}$ Reference permeability $\mathrm{K}_{0,1}=10^{-13}$ is a reference case. Other permeability values, $\mathrm{K}_{0,1}=\left\{10^{-11}, 10^{-15}\right\}$, were also tested.

** Reference permeability $\mathrm{K}_{0,1}$ and characteristic seepage $\mathrm{v}_{\mathrm{c}}$ are related. For $\mathrm{K}_{0,1}=10^{-11}, \mathrm{v}_{\mathrm{c}}=10^{-4}$ and for $\mathrm{K}_{0,1}=10^{-15}, \mathrm{v}_{\mathrm{c}}=10^{-8}$

Figure 1. REV, test setting, and parameters. 

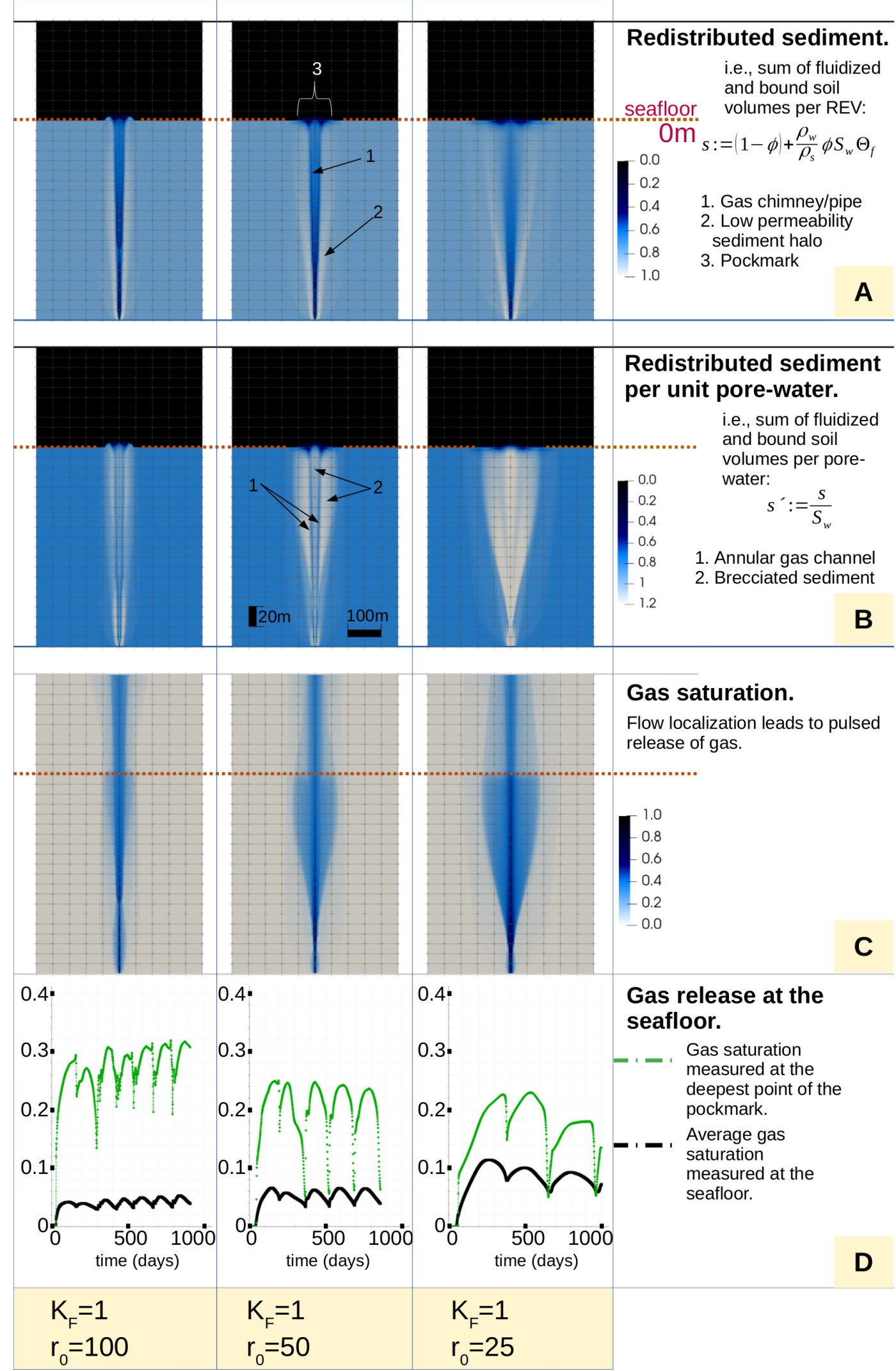

Figure 2. Impacts of relative erodibility $r_{0}$ on sediment redistribution, gas flow, and morphology of pockmark and pipe/chimney. 

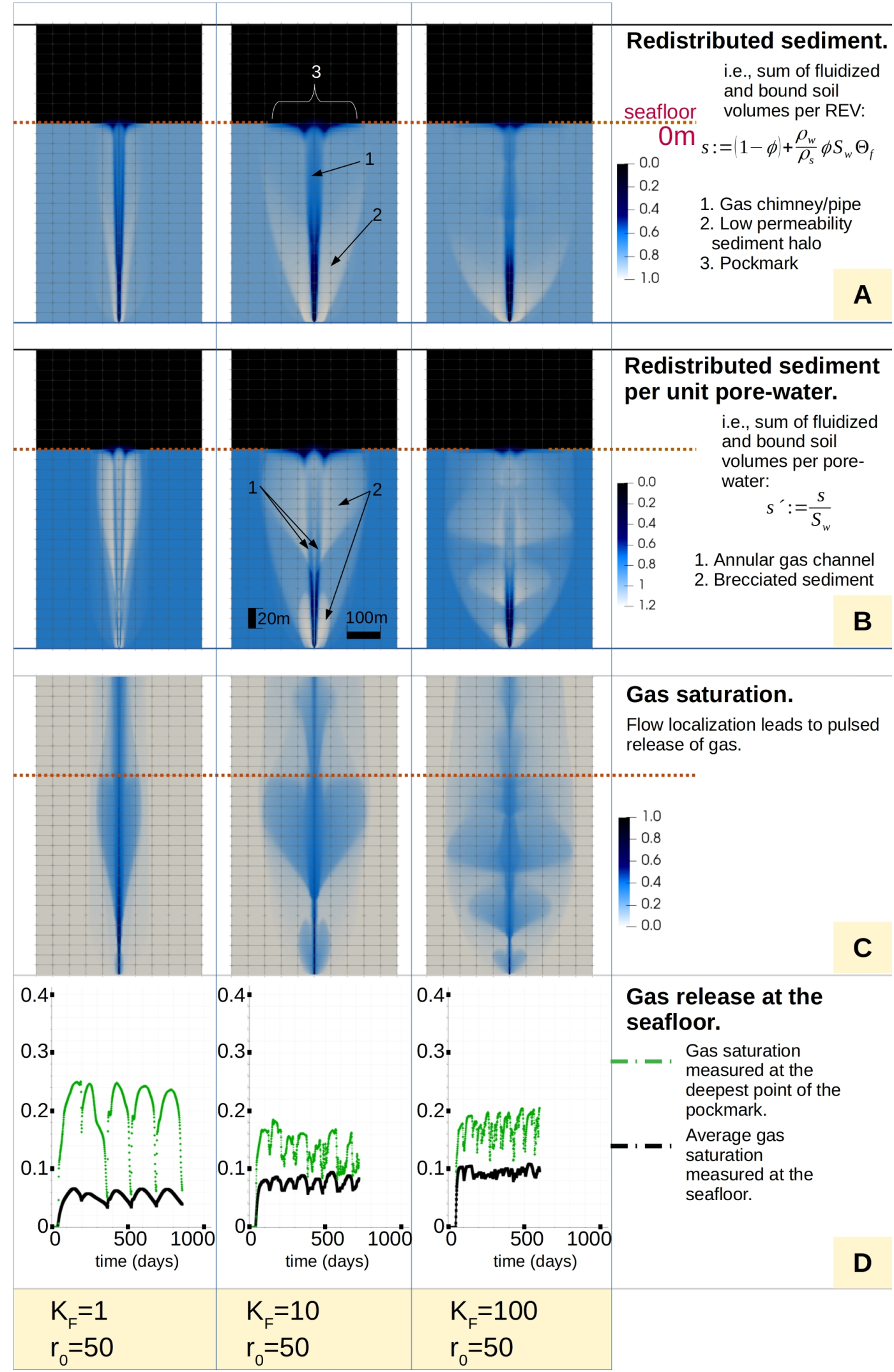

Figure 3. Impacts of sediment anisotropy $K_{F}$ on sediment redistribution, gas flow, and morphology of pockmark and pipe/chimney. 


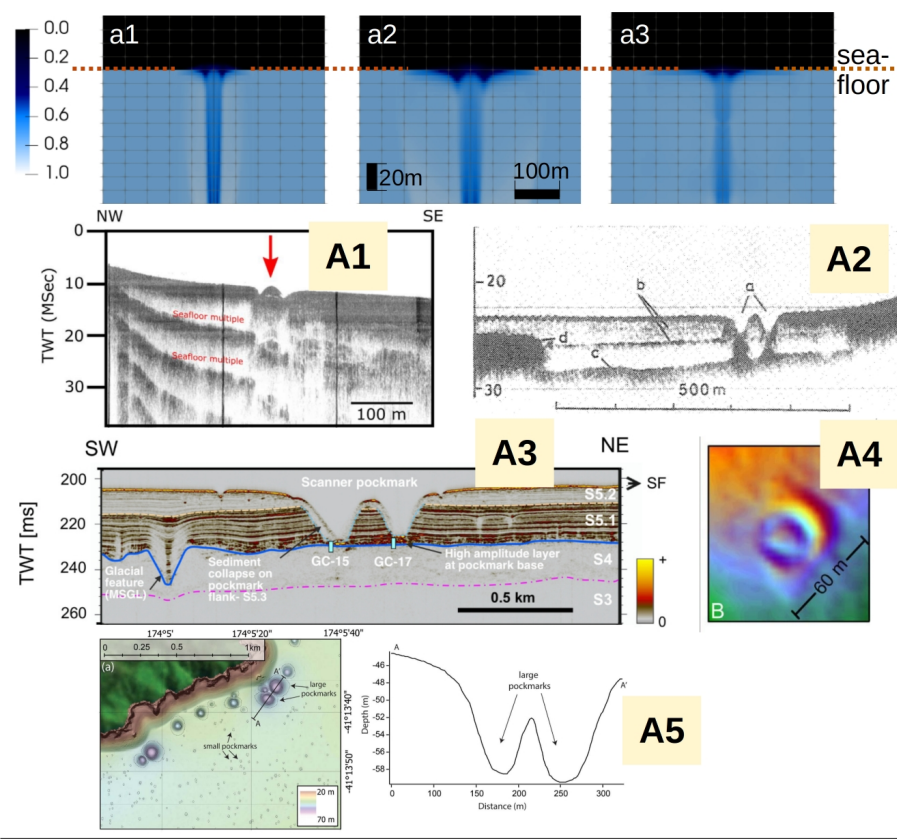

\section{W-shaped pockmarks}

A1: Radially symmetric a1: $\mathrm{K}_{\mathrm{F}}=1, \mathrm{r}_{0}=50$ (with inverted-dome) pockmark in Sea of a2: $\mathrm{K}_{\mathrm{F}}=10, \mathrm{r}_{0}=50$ (2019)]

a3: $K_{F}=100, r_{0}=50$

A2: Pockmark pair in

Eckenförder Bay in

Baltic Sea [Hovland

(1988), pg. 71].

A3: Pockmark pair (or compound pockmark)

in the Scanner region

[Callow et. al (2021)]

A4: Radially symmetric

pockmark offshore

northern Israel

[Schattner et. al (2012)]

A5: Pockmark pair in a drowned river valley

in New Zealand

[Watson et. al (2021)]
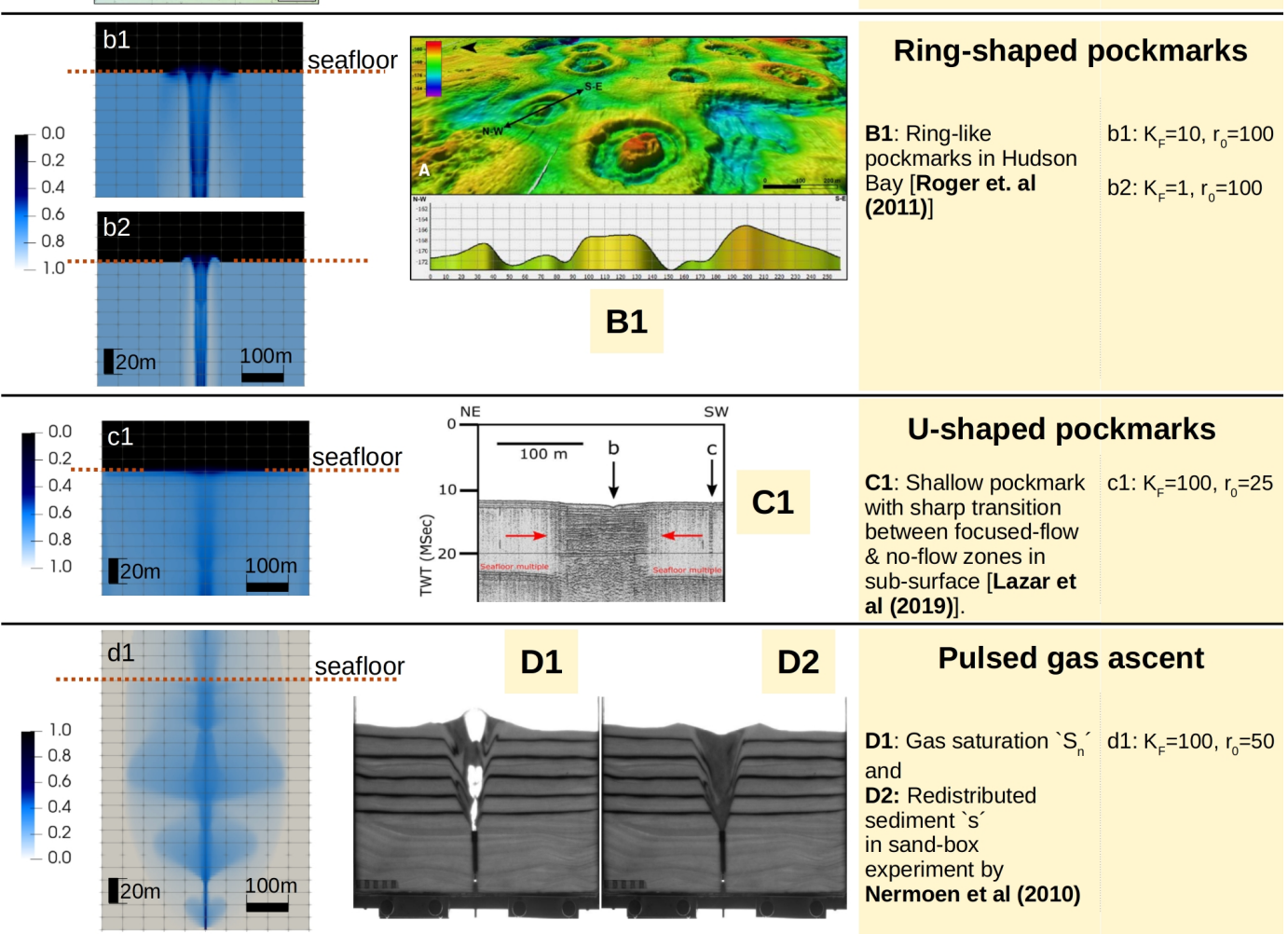

Figure 4. Qualitative similarities between simulated pockmarks (a1-3, b1-2, c1, d1-2) and those reported in literature (A1-5, B1, C1, D1-2). Pockmarks are compared on the basis of shapes, i.e. (A1-5;a1-3) W-, (B1;b1,2) ring-, and (C1;c1) U-shapes. Also shown are (D1,2) sandbox experiment results, and its similarity with (d1) simulated gas ascent behaviour. 
A Redistributed sediment.

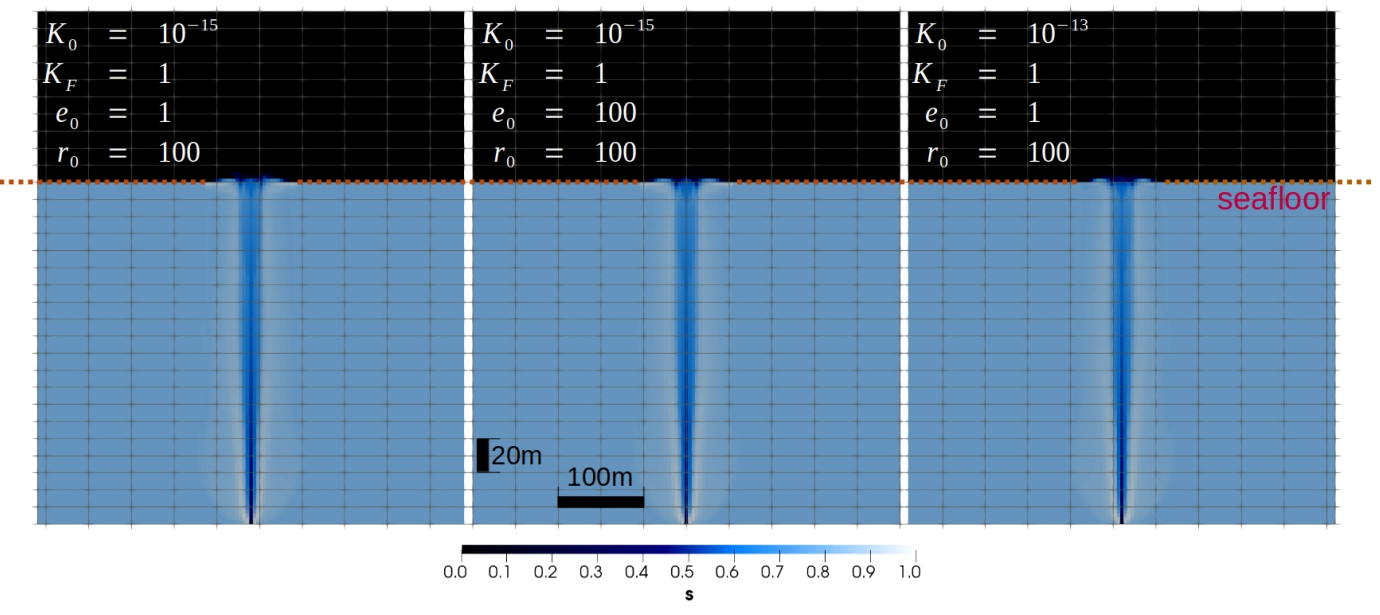

B Gas saturation.

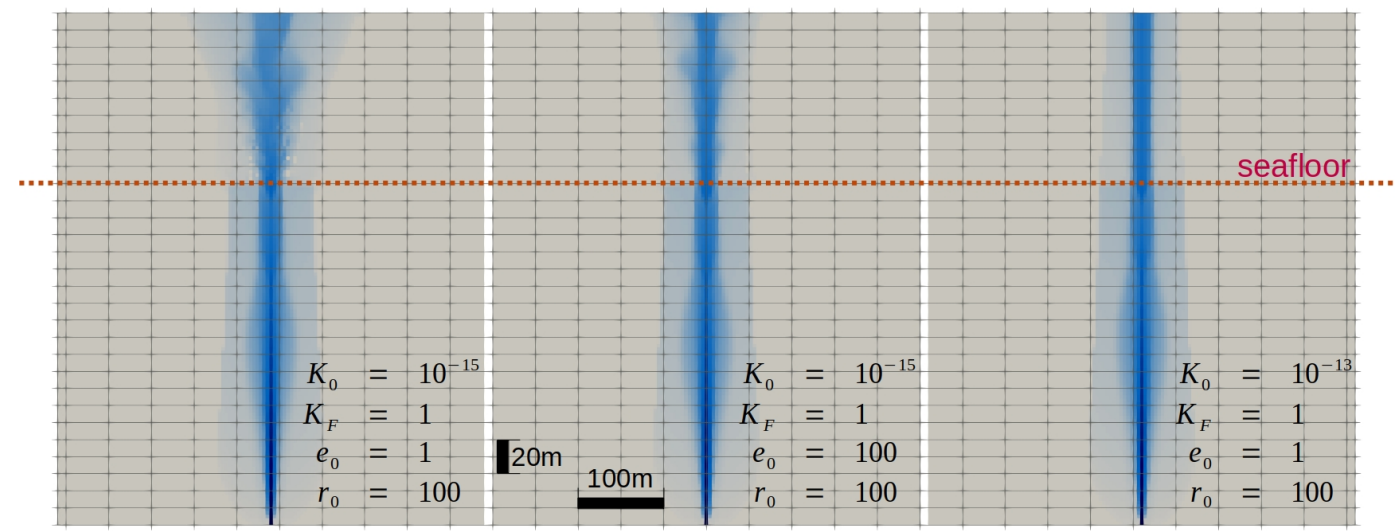

\begin{tabular}{ccccccccccc}
0. & 0.1 & 0.2 & 0.3 & 0.4 & 0.5 & 0.6 & 0.7 & 0.8 & 0.9 & 1. \\
\hline & 1 & 1 & 1 & 1 & 1 & 1. & &
\end{tabular}

Figure 5. Impacts of intrinsic permeability $K_{0,1}$ and erosion rate constants $e_{0}$ on the evolution of surface and subsurface morphological features as well as the gas flow behaviour. Snapshots for scenarios with $K_{0,1}=10^{-15} \mathrm{~m}^{2}$ correspond to time $t=100$ years, while those with $K_{0,1}=10^{-13} m^{2}$ correspond to $t=1$ year. 